Research Article

\title{
Phytogenic Synthesis and Characterization of NiO-ZnO Nanocomposite for the Photodegradation of Brilliant Green and 4-Nitrophenol
}

\author{
Sirajul Haq ${ }^{D},{ }^{1}$ Aqsa Waheed Raja, ${ }^{1}$ Sadiq Ur Rehman, ${ }^{1}$ Amine Mezni, ${ }^{2}$ Manel Ben Ali, \\ Amor Hedfi, ${ }^{3}$ Muhammad Imran Shahzad, ${ }^{4}$ Wajid Rehman, ${ }^{5}$ Nadia Shahzad, \\ Muhammad Waseem, ${ }^{7}$ and Pervaiz Ahmad ${ }^{8}$ \\ ${ }^{1}$ Department of Chemistry, University of Azad Jammu and Kashmir, Muzaffarabad 13100, Pakistan \\ ${ }^{2}$ Department of Chemistry, College of Science, Taif University, P.O. Box 11099, Taif 21944, Saudi Arabia \\ ${ }^{3}$ Department of Biology, College of Sciences, Taif University, P.O. Box 11099, Taif 21944, Saudi Arabia \\ ${ }^{4}$ Nanosciences and Technology Department (NS \& TD), National Center for Physics (NCP), 44000 Islamabad, Pakistan \\ ${ }^{5}$ Department of Chemistry, Hazara University Mansehra, Mansehra 21300, Pakistan \\ ${ }^{6}$ US-Pakistan Centre for Advanced Studies in Energy, National University of Science and Technology (NUST), \\ 44000 Islamabad, Pakistan \\ ${ }^{7}$ Department of Chemistry, COMSATS University Islamabad (CUI), Islamabad, Pakistan \\ ${ }^{8}$ Department of Physics, University of Azad Jammu and Kashmir, 13100 Muzaffarabad,, Pakistan
}

Correspondence should be addressed to Sirajul Haq; cii_raj@yahoo.com

Received 7 August 2021; Revised 17 September 2021; Accepted 20 September 2021; Published 13 October 2021

Academic Editor: Christos Kordulis

Copyright (c) 2021 Sirajul Haq et al. This is an open access article distributed under the Creative Commons Attribution License, which permits unrestricted use, distribution, and reproduction in any medium, provided the original work is properly cited.

\begin{abstract}
The $\mathrm{NiO}-\mathrm{ZnO}$ nanocomposite ( $\mathrm{NiO}-\mathrm{ZnO} \mathrm{NC}$ ) was synthesized by ecofriendly process by using Diospyros kaki (D. kaki) extract of leaves as reducing and capping agents. X-ray diffraction (XRD) was used for examined crystallinity, cell dimensions, and crystallite size $(7.6 \mathrm{~nm})$. To determine the purity of sample and weight percentage, energy dispersive X-ray (EDX) is used. The surface morphology was determined by scanning electron microscopy (SEM) and transmission electron microscopy (TEM). By using Fourier transform infrared spectroscopy (FTIR), functional groups in samples were determined. By using diffuse reflectance data (DRS), band gap energy calculated via Tauc plot was $3.23 \mathrm{eV}$. The photocatalytic activity was checked against brilliant green (BG) and 4-nitrophenol (4-NP) and $92.5 \%$ and $69.7 \%$ of brilliant green (BG) and 4-nitrophenol (4-NP) were degraded with rate of degradation which were 0.0281 and $0.011 \mathrm{~min}^{-1}$.
\end{abstract}

\section{Introduction}

Due to industrial revolution, environmental pollution exponentially increases with passage of time by releasing carcinogenic and mutagenic hazardous wastes and their side products to aqueous environment $[1,2]$. Major contributors of water and air contamination are food, paper, textile, and pharmaceutical industries; among these, textile industries produce many toxic substances, and due to nonbiodegradability and stability of organic pollutants, they are considered deadly $[3,4]$. Different dyes such as methylene blue, golden yellow, and eriochrome black $\mathrm{T}$ have wide range of applications, but they are lethal for all life forms [5-7]. Brilliant green is used in paper printing and coloring silk, but its effects investigated on bacteria and rats alarming destruction were noted in their renal tissues and reproductive systems, so presence of these types of organic dyes in water impose threat that is why purification and detoxification of air and water are necessary to ensure safe of human and aquatic life. As listed by US-EPA, 4-nitrophenol is a cancercausing pollutant [8]. Researchers are continuously searching to find effective and ecofriendly ways to eradicate 
these toxic dyes and metals from water [9, 10]. Different methods are in practice for eradication of dyes such as adsorption, membrane filtration, biological treatment, electrochemical treatment, photocatalytic degradation, ozonation, oxidation, chemical precipitation, and ion exchange [11]. Photocatalysis is cost-effective, environmentfriendly method for removal of dyes where the photocatalysts such as $\mathrm{NiO}, \mathrm{TiO}_{2}, \mathrm{SnO}_{2}, \mathrm{ZnO}$, and $\mathrm{WO}_{3}$, are used for removing dyes [4]. Development of photocatalytic technology improves the water quality [12]. With the advancement, composite materials provide an opportunity to prepare cost-effective and efficient products in limited resources [13]. Nanocomposite has gained double interest in photocatalysis due to their better light harvesting property compared to individual components. $\mathrm{NiO}-\mathrm{Bi}_{2} \mathrm{O}_{3}$ composite is helpful to disintegrate dyes such as methyl orange and methylene blue. Composite photocatalysts also improve the problems of photocatalysed reactions such as light response and low efficiencies [14]. Bimetallic composite shows better magnetic, thermal, catalytic, and optical properties [15]. Nanocomposites of $\mathrm{ZnO}-\mathrm{NiO}$ are used as photocatalysts and have better properties than their individual particles and their efficiency increases by increasing $\mathrm{NiO}$ concentration [4]. $\mathrm{NiO} / \mathrm{ZnO}$ nanocomposite is used in transparent conducting thin films for OLED applications [16]. These composites possess great photocatalytic activity against dyes such as methylene blue and Rhodamine B [17].

In the recent past, different methods such as combustion method, coprecipitation method, and sonochemical route had been employed to synthesize $\mathrm{NiO}-\mathrm{ZnO}$ composites $[4,18]$. However, these methods include the used toxic precursor chemical, solvents, and reducing and stabilizing agents along with expensive instruments. Recently, nanoparticles have widely been synthesized by green method by using plant extract and microorganisms as reducing and capping agents. Among different biosynthetic methods, the use of plant extract is more advantageous due to safe handling and easy availability [19]. In this research work to synthesize $\mathrm{NiO}-\mathrm{ZnO} \mathrm{NC}, \mathrm{D}$. kaki leaves extract was used and was analyzed by SEM, XRD, EDX, FTIR, and DRS. The synthesized composite used was photodegradation of BG and 4-NP in its aqueous solution under sunlight. Mathematical equations were used for determining percentage degradation and rate constant.

\section{Materials and Method}

2.1. Materials. Highly pure chemicals containing nickel chloride hexahydrate, zinc chloride hexahydrate, sodium hydroxide, brilliant green, and 4-nitrophenol were purchased from Sigma-Aldrich and were used without more purification. D. kaki leaves extract and the working solutions were prepared in deionized water.

2.2. Preparation of Plant Leaves Extract. The collected leaves of $D$. kaki were washed with tap water along with deionized water and were dried in shade. For the extract preparation, $50 \mathrm{~g}$ of $\mathrm{D}$. kaki leaves were added to a beaker containing
$1000 \mathrm{~mL}$ distilled water and boiled for three hours. The crude extract obtained was filtered, centrifuged, and stored at $4^{\circ} \mathrm{C}$.

2.3. Synthesis of $\mathrm{NiO}-\mathrm{ZnO} \mathrm{NC}$. To make precursor salt solution, $2.24 \mathrm{~g}$ of nickel sulphate hexahydrate was added in $50 \mathrm{~mL}$ deionized water and then mixed with $20 \mathrm{~mL}$ of $D$. kaki extract and the $\mathrm{pH}$ was adjusted at 8 by adding $\mathrm{NaOH}$ solution. For $30 \mathrm{~min}$ at $60^{\circ} \mathrm{C}$, the reaction mixture was heated and the gel obtained was marked as solution A. Similarly, the zinc sulphate hexahydrate solution was synthesized by dissolving $2.20 \mathrm{~g}$ dissolved in $50 \mathrm{~mL}$ deionized water and mixed with $20 \mathrm{~mL}$ leaves extract of D. kaki. The $\mathrm{pH}$ was maintained at 10 by adding $\mathrm{NaOH}$ solution and the mixture was stirred and heated $\left(60^{\circ} \mathrm{C}\right)$ for $30 \mathrm{~min}$ and the gel formed was marked as solution $\mathrm{B}$. To synthesize NiO$\mathrm{ZnO} \mathrm{NC}$, both gels (solutions $\mathrm{A}$ and $\mathrm{B}$ ) were mixed together and for four hours stirred at $70^{\circ} \mathrm{C}$. The solid product obtained was left for overnight cooling at room temperature and was then washed thrice with distilled water. The end product was dried up in electric oven at $150^{\circ} \mathrm{C}$ and stored in air tight bottle of polyethylene.

2.4. Characterization. The $\mathrm{KBr}$ pellet was analyzed by FTIR model Nicolet 6700 (USA) in the range of 4000 to $400 \mathrm{~cm}^{-1}$ to identify the functional groups present on the surface of the sample. The DRS model Lambda 950 was run in between 400 and $1000 \mathrm{~nm}$ and band gap energy was determined through Tauc plot. The XRD pattern was recorded in the range of 20 to 80 utilizing Panalytical X-Pert Pro, where $\mathrm{Cu}$ source was used. The FWHM values of the diffraction peaks were used to calculate the crystallite size. The morphological analysis was carried out through SEM model 5910 (Japan) and Hitachi H7700 TEM with an accelerating voltage of $100 \mathrm{kV}$, where sample was steak with sticky carbon tape. The EDX model INCA 200 (UK) coupled with SEM was operated from elemental analysis.

2.5. Photodegradation Assay of BG and 4-NP. The photocatalytic experiments were performed second week of June, 2020 , from 11 am to $3 \mathrm{pm}$. The temperature in these days was ranging from 38 to $45^{\circ} \mathrm{C}$, where the UV index was lying between 9 and 12. Photocatalytic efficiency of $\mathrm{NiO}-\mathrm{ZnO} \mathrm{NC}$ was checked by the photodegradation of BG, where $20 \mathrm{mg}$ of the synthesized catalyst was added to $50 \mathrm{~mL}(10 \mathrm{ppm})$ solution of dye. To ensure the dispersion of a catalyst in dye solution, we stirred mixture in dark for $30 \mathrm{~min}$ to the attained adsorption-desorption equilibrium. The reaction mixture was exposed to solar light and the decrease in the absorbance maxima was monitored after a specific interval of time (min). Sufficient volume of sample was analyzed via UV spectrophotometer and absorbance was decreased which was recorded as against time.

The photodegradation of 4-nitrophenol by $\mathrm{NiO}-\mathrm{ZnO}$ $\mathrm{NC}$ was checked by taking $10 \mathrm{mg}$ of NC and we added it into aqueous solution of 4-nitrophenol at room temperature. The reaction mixture was stirred for half an hour to attain adsorption-desorption equilibrium. Afterward, the reaction 
was exposed to sunlight, and after regular interval, the sample was taken and centrifuged, and decrease in absorbance was checked in UV-Vis spectrophotometer by determining absorbance at $318 \mathrm{~nm}$. The mathematical equations (equations (1) and (2)) were applied to determine photocatalytic reaction parameters [20].

$$
\begin{aligned}
\% \text { degradation } & =\frac{C_{o}-C_{e}}{C_{o}} \times 100, \\
\ln \left(\frac{C}{C_{O}}\right) & =-k t .
\end{aligned}
$$

\section{Result and Discussion}

3.1. FTIR Analysis. FTIR spectroscopic analysis of $\mathrm{NiO}-\mathrm{ZnO}$ NC (Figure 1(a)) shows that presence of transmittance band in the range of $3591-3222 \mathrm{~cm}^{-1}$ shows stretching vibration of hydroxyl group attached with metal center [21]. The peak originated at $2339 \mathrm{~cm}^{-1}$ depicts atmospheric $\mathrm{CO}_{2}$ adsorbed on the surface of synthesized nanocomposite [22]. The peaks at $1642 \mathrm{~cm}^{-1}$ and $1506 \mathrm{~cm}^{-1}$ are due to bending vibration of $\mathrm{OH}$ bond in plane and out of plane, respectively $[21,22]$. The peak visible at $1379 \mathrm{~cm}^{-1}$ and $1116 \mathrm{~cm}^{-1}$ corresponds to $\mathrm{OH}$ group [23]. The peak at $1047 \mathrm{~cm}^{-1}$ region indicates $\mathrm{Zn}-\mathrm{O}$ bond [22], whereas the peak appeared at $952 \mathrm{~cm}^{-1}$ is due to $\mathrm{Ni}-\mathrm{O}$ stretching vibrations [24]. The peaks at $685 \mathrm{~cm}^{-1}$ and $590 \mathrm{~cm}^{-1}$ show nickel and zinc metal oxides, respectively [21]. The FTIR spectrum of D. kaki: Figure 1(b) exhibits characteristic FTIR peaks at 3466, 3010, 2971, 1715.53, $1424.33,1357.03,1220.84,1092.54,895.57,793.91$, and $529.54 \mathrm{~cm}^{-1}$ attributed to the stretching of O-H, C-H (aromatic), $\mathrm{C}-\mathrm{H}$ (aliphatic), $\mathrm{C}=\mathrm{O}, \mathrm{C}=\mathrm{C}, \mathrm{N}-\mathrm{O}$ in $\mathrm{NO}_{3}, \mathrm{C}-\mathrm{N}$ of primary amine, and C-X (halogen), respectively [25]. The phenolic compounds in the leaf extract of $D$. kaki are responsible for the reduction of precursor's salt and capping of the metal cation, as shown in Figure 2 [26].

3.2. DRS Analysis. Diffuse reflectance spectroscopy (DRS) is useful technique for the determination of band gap which in turn provides base of mechanism of photocatalysis. The absorbance spectrum recorded in the range of 250-1200 nm for $\mathrm{NiO}-\mathrm{ZnO} \mathrm{NC}$ is given in Figure 3, which shows maximum absorbance in the UV range. The absorbance was successively decreased with increasing wavelength suggesting that the electronic transition occurred in UV range. From the absorption edges of reflectance spectra, band gap is calculated by using Tauc plot (inset in Figure 3 ) by using the following equation:

$$
(\alpha h \nu)=C(h \nu-E g)^{n},
$$

where $\alpha$ is the absorption coefficient of material, $h$ is Plank's constant, $v$ is the frequency, $C$ is the proportionality constant, $E g$ is the band gap energy, and the exponent $n$ can have values of $1 / 2,2,3 / 2$, or 3 depending on the type of transition: direct, forbidden direct, indirect, or forbidden indirect. The optical energy band gap of $\mathrm{NiO}-\mathrm{ZnO} \mathrm{NC}$ is $3.34 \mathrm{eV}$.
3.3. SEM Analysis. SEM is a valuable technique to determine surface morphology and particle size. The low and high magnified SEM micrographs of the NiO-ZnO NC are presented in Figure 4. The micrographs show that after the dehydration, compact solid structures are formed. Several small particles with definite boundaries are seen on the surface of the hard solid structures that have no specific shape and size.

3.4. TEM Analysis. The TEM micrograph at a resolution of 70000, given in Figure 5, shows that the particles are embedded in an amorphous layer. Probably, the layer is composed of phytochemicals that exist in the aqueous extract of $D$. kaki. The majority of the particles are highly agglomerated, forming a compact structure where the boundaries between the particles are indistinguishable. However, some well-defined oval/nearly spherical particles are also seen in the image, which exhibit lucent boundaries. The particle size estimated ranges from $48.84 \mathrm{~nm}$ to $79.05 \mathrm{~nm}$, with an average size of $63.24 \mathrm{~nm}$.

3.5. XRD Analysis. The XRD data of $\mathrm{NiO}-\mathrm{ZnO} \mathrm{NC}$ are presented in Figure 6, possessing Bragg's reflections for both $\mathrm{NiO}$ and $\mathrm{ZnO}$. The diffraction bands for $\mathrm{NiO}$ had appeared at $2 \theta$ position 33.19 and $59.91^{\circ}$ corresponding to hkl values (001) and (110), respectively. These peaks corresponding to monoclinic phase of $\mathrm{NiO}$ are having space group $\mathrm{C}_{2} / \mathrm{m}$ with cell constants $a=5.11, b=2.95$, and $c=2.95 \AA$ as per reference card (01-072-1464). The Bragg's signals for $\mathrm{ZnO}$ appeared at $2 \theta$ position along with hkl values $31.74(100)$ and 35.74(101) attributed to hexagonal geometry of $\mathrm{ZnO}$ with a space group of P63mc where the cell constants are $a=3.24$, $b=3.24$, and $c=5.20$ corresponding to JCPDS card (000361451). The XRD pattern exhibits peaks for both $\mathrm{NiO}$ and $\mathrm{ZnO}$ suggesting the formation of hetero-structure, whereas the noisy spectrum suggests the presence of some amorphous content in the sample. The Scherer formula was used to calculate the crystallite size $(7.62 \mathrm{~nm})$ considering the FWHM values of diffraction bands, where $\beta$ is full width at half maximum and $\lambda$ is the $\mathrm{X}$-ray wavelength.

$$
t=\frac{0.9 \lambda}{\beta \cos \theta} \text {. }
$$

3.6. EDX Analysis. The EDX is a significant technique to determine the chemical composition [27]. EDX spectrum is shown in Figure 7, which reveals that the elements within synthesized $\mathrm{NiO}-\mathrm{ZnO} \mathrm{NC}$ are nickel, zinc, oxygen, and carbon. The existence of carbon in the sample may point the use of plant during synthesis or it may also be due to the use of carbon tape during analysis. The short signal appeared at $0.2 \mathrm{keV}$ is of carbon, due to the use of carbon tape during study, or might be because of plant materials. The medium band at $0.6 \mathrm{keV}$ assigned to oxygen $(\mathrm{O})$ is due to the formation of oxide of $\mathrm{Ni}$ and $\mathrm{Zn}$. The signals at $0.9,7.5$, and $8.2 \mathrm{eV}$ are because of nickel, whereas the bands appeared at $1,8.6$, and $9.5 \mathrm{eV}$ attributed to the presence of zinc in 


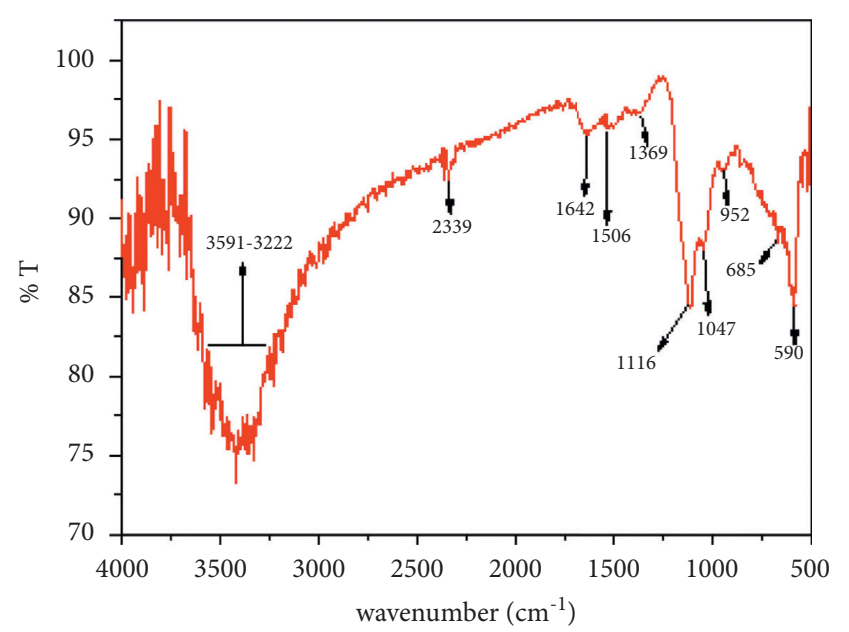

(a)

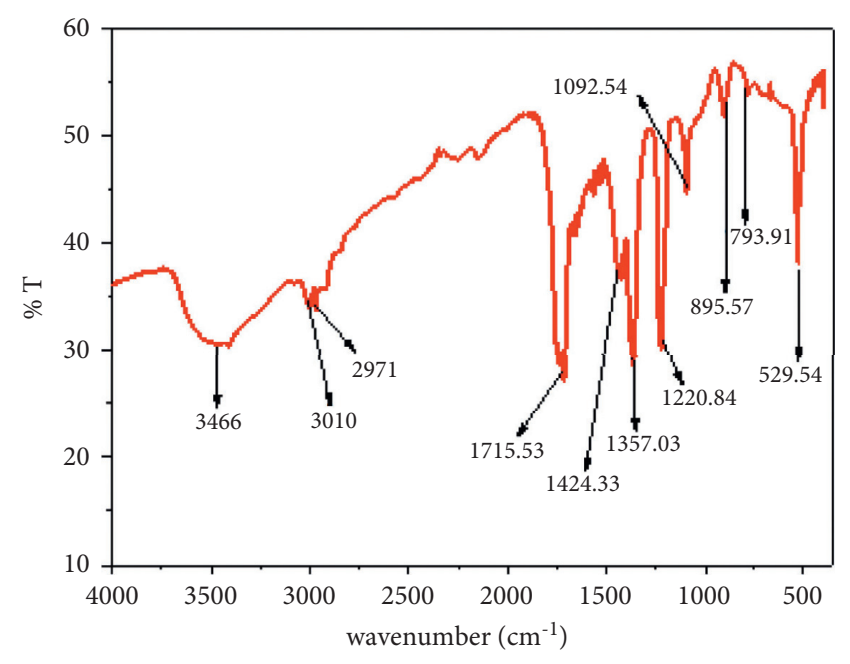

(b)

Figure 1: (a) FTIR spectrum of NiO-ZnO NC and (b) FTIR spectrum of D. kaki.

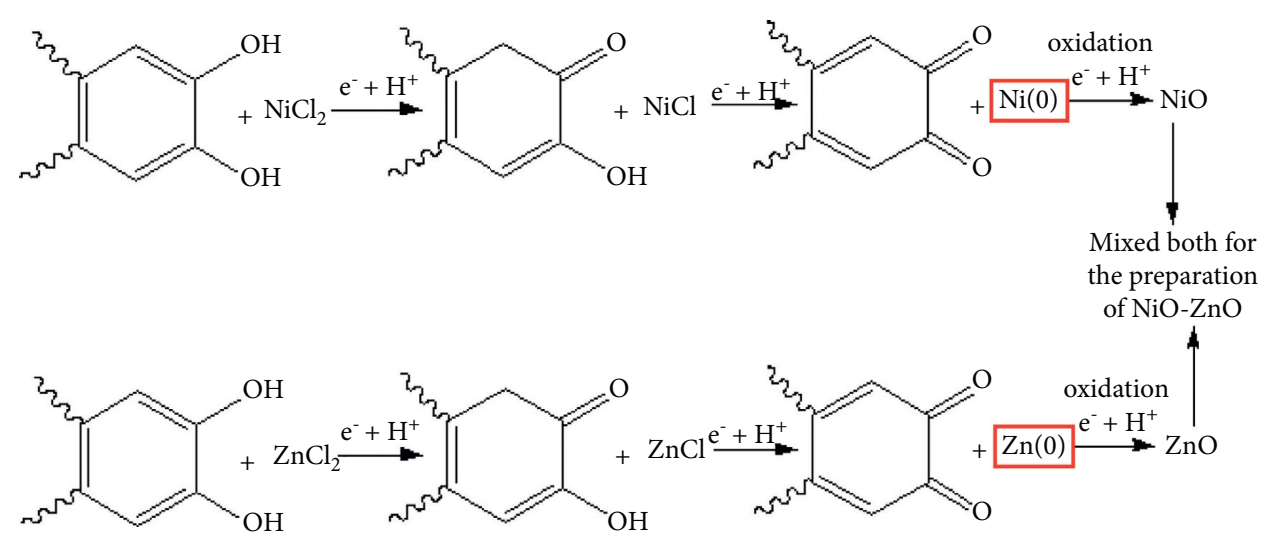

Figure 2: Proposed mechanism for the green synthesis of $\mathrm{NiO}-\mathrm{ZnO} \mathrm{NC}$.

product. The weight percentages of carbon, nickel, zinc, and oxygen estimated by EDX analysis are 1.03, 13.98, 32.50, and $52.43 \%$, respectively. The EDX results were found comparable with those reported by Karthikeyan et al. [28].

3.7. Photocatalytic Activity. The NiO-ZnO NC prepared by green method was used as photocatalyst for the deterioration of BG and 4-NP. Before the photocatalytic experiment, a self-photolysis experiment was carried out in the absence of catalyst, and after $90 \mathrm{~min}$, a slight decrease was seen in the absorbance maxima and determined percent degradation was found to be $2.78 \%$. To degrade, $\mathrm{BG}$ reaction was carried out in sun radiations during $11 \mathrm{am}$ to $2 \mathrm{pm}$. For the photocatalytic experiment, $20 \mathrm{mg}$ of catalyst was added into $50 \mathrm{~mL}$ of BG solution (10 ppm) and stirred in dark for $30 \mathrm{~min}$ for establishing adsorption-desorption equilibrium [20]. After that, the mixture was placed under sunlight, and with the passing time, the decrease in the absorbance maxima was noted, as shown in Figure 8(a). Similar procedure was repeated for 4-NP and the results obtained are given in
Figure 9(a). The activity of pure $\mathrm{NiO}-\mathrm{ZnO} \mathrm{NC}$ was checked in terms of percentage degradation, which was calculated by applying equation (2). The percentage degradation of BG was determined to be $92.5 \%$ after $90 \mathrm{~min}$ (Figure $8(\mathrm{~b})$ ), whereas $69.7 \%$ of the 4 -NP was degraded in $45 \mathrm{~min}$, as shown in Figure 9(b). The kinetics for the photocatalytic reaction was determined by using Langmuir-Hinshelwood equation (equation (2)) and the straight line obtained (Figures 8(c) and 9(d)) suggest the reaction follows pseudofirst order and the determined rate constant is $2.8 \times 10^{-2}$ $\min ^{-1}$ and $1.13 \times 10^{-2} \mathrm{~min}^{-1}$ for BG and 4-NP, respectively. The stability/reusability of the $\mathrm{NiO}-\mathrm{ZnO} \mathrm{NC}$ was checked by addition of fresh BG solution into the reactor under same reaction condition. The process was repeated for four times under the same condition, and the data obtained are shown in Figure $7(d)$, which shows during the initial experiment, the mineralization rate was high and a gradual reduction was seen in afterward cycles. The percent degradation was recorded to be $92.52,90.38,87.69$, and $84.30 \%$ during $1^{\text {st }}$, $2^{\text {nd }}, 3^{\text {rd }}$, and $4^{\text {th }}$ cycles, respectively. This shows the stability of the synthesized $\mathrm{NiO}-\mathrm{ZnO} \mathrm{NC}$ and can be used for several 


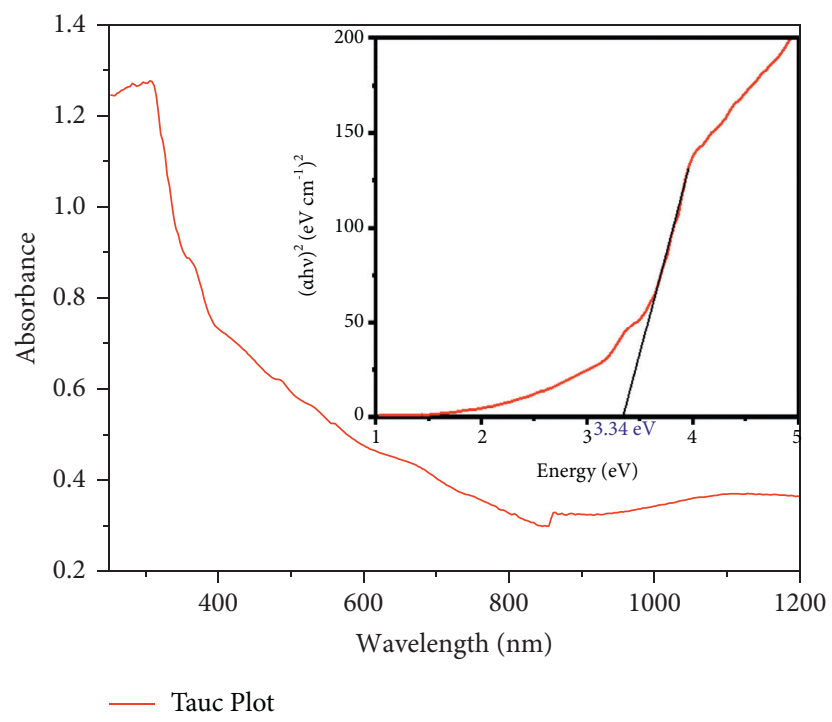

FIgURE 3: DRS spectrum (inset: Tauc plot) of NiO-ZnO NC.

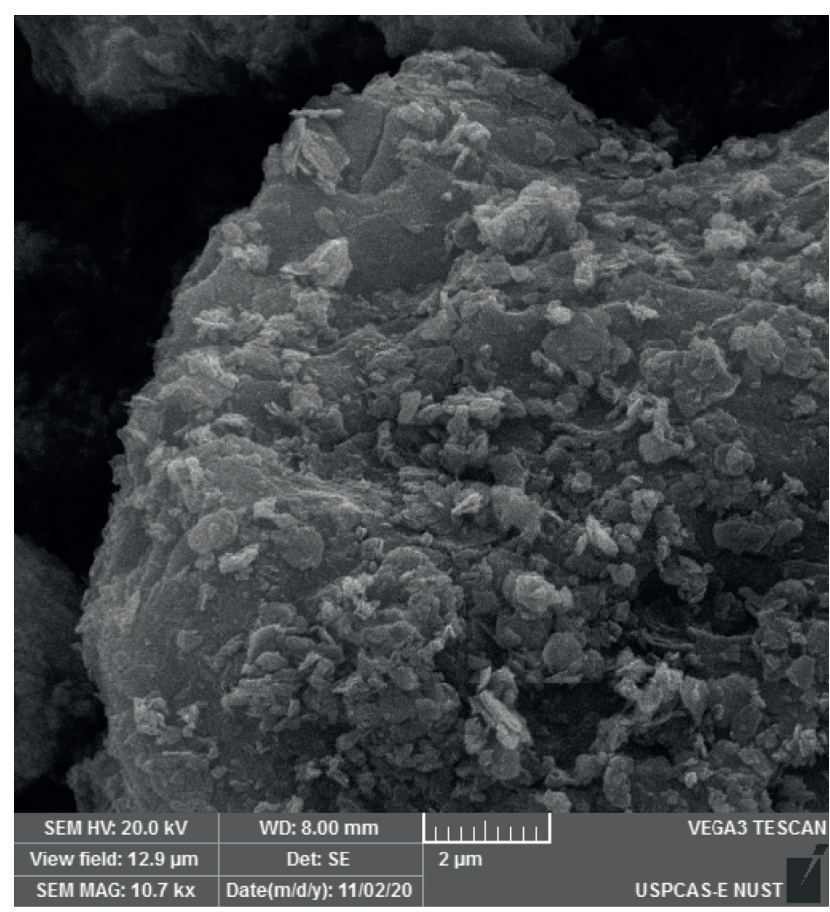

(a)

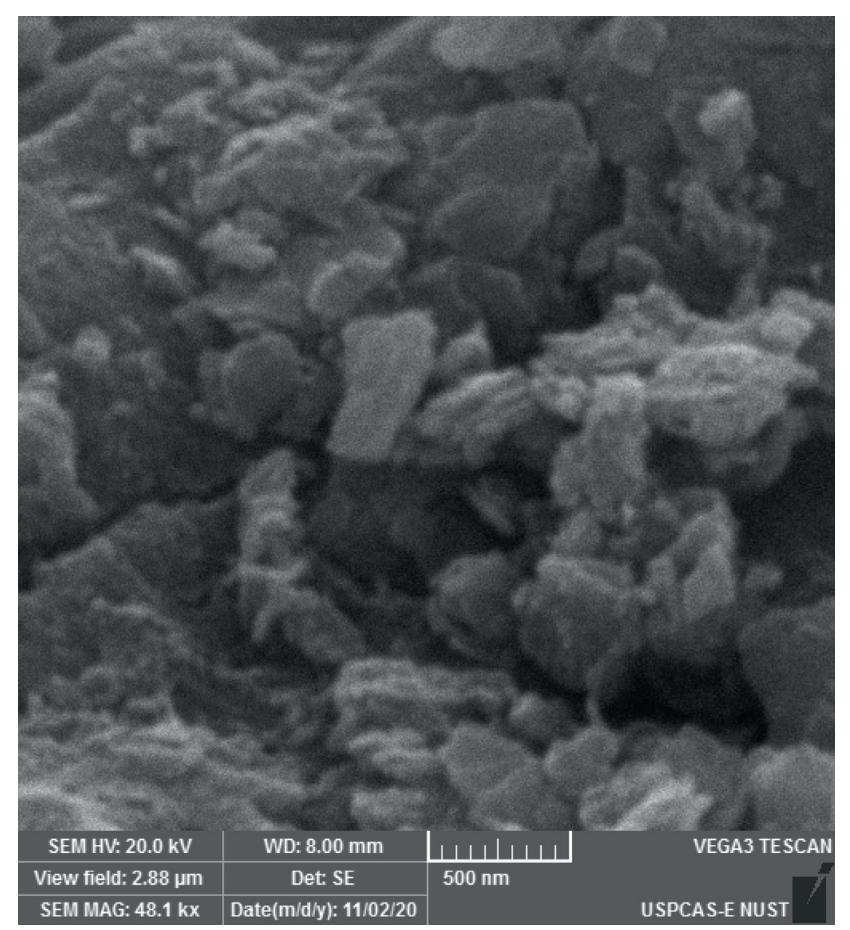

(b)

FIgURE 4: Low (a) and high (b) magnification SEM micrographs of NiO-ZnO NC.

step degradations of organic pollutants. The photocatalytic activity of synthesized $\mathrm{NiO}-\mathrm{ZnO} \mathrm{NC}$ was compared against other organic dyes, as shown in Table 1.

When solar radiations having energy equal or greater than catalyst's band gap fall on $\mathrm{NiO}-\mathrm{ZnO}$ NC surface, valence electrons of both oxides of nickel and zinc get excited to the conduction band and positive holes get created in the valance band. The photo-generated electrons from conduction band of $\mathrm{NiO}$ get transferred to the conduction band of $\mathrm{ZnO}$, whereas the positive holes get shifted from $\mathrm{ZnO}$ to $\mathrm{NiO}$, thus keeping the electrons and holes apart as shown in Figure 10 [29]. Photo-generated holes react with the water or surface hydroxyl group and form hydroxyl radical and photo-induced electrons produce superoxide anion by reacting with oxygen which by further reaction produces hydroxyl radicals. These hydroxyl radicals degrade 


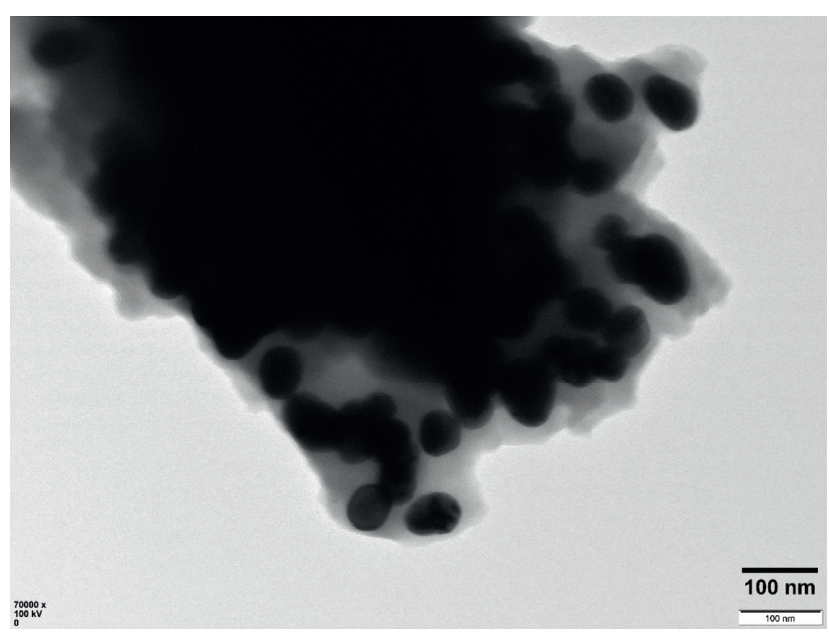

Figure 5: TEM micrograph of $\mathrm{NiO}-\mathrm{ZnO} \mathrm{NC}$.

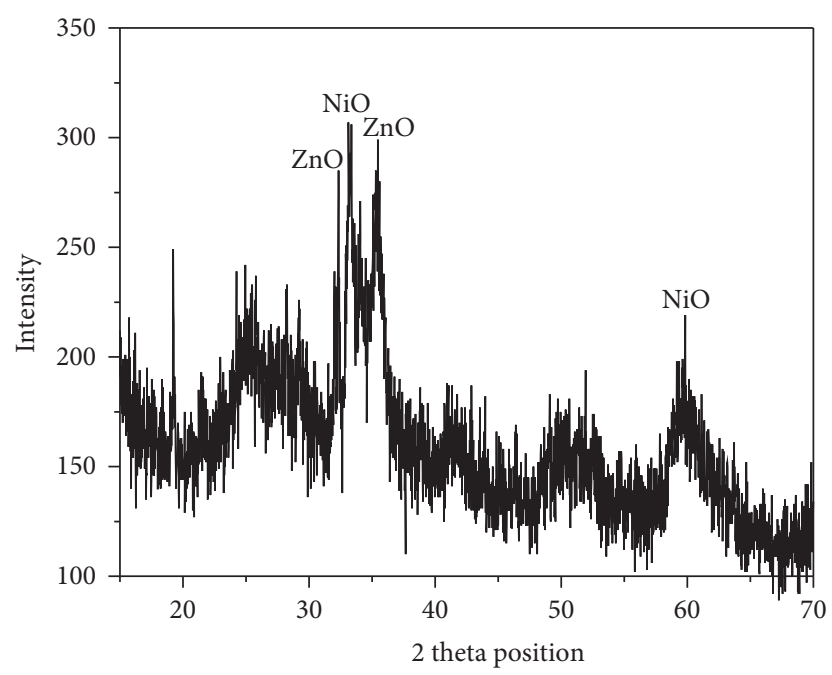

Figure 6: X-ray diffractogram of $\mathrm{NiO}-\mathrm{ZnO} \mathrm{NC}$.

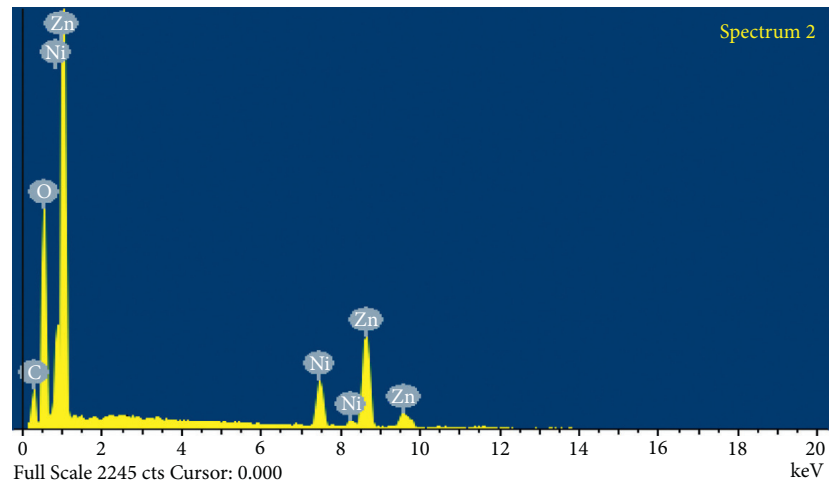

Figure 7: EDX spectrum of NiO-ZnO NC. 


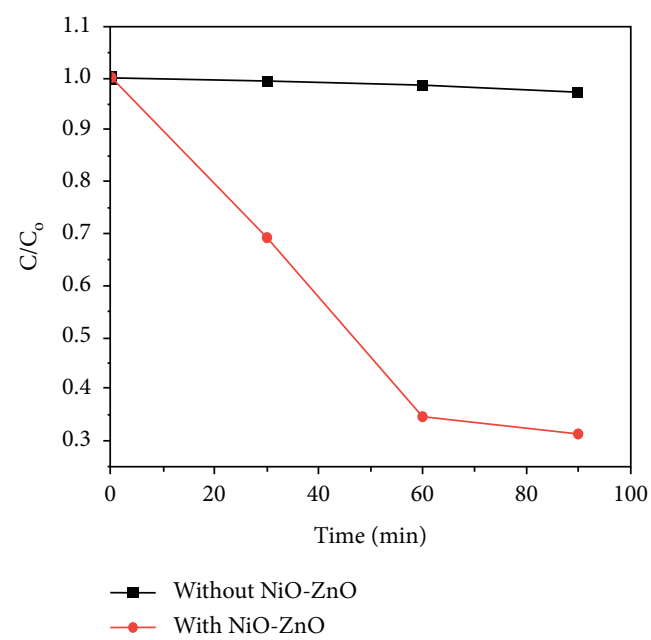

(a)

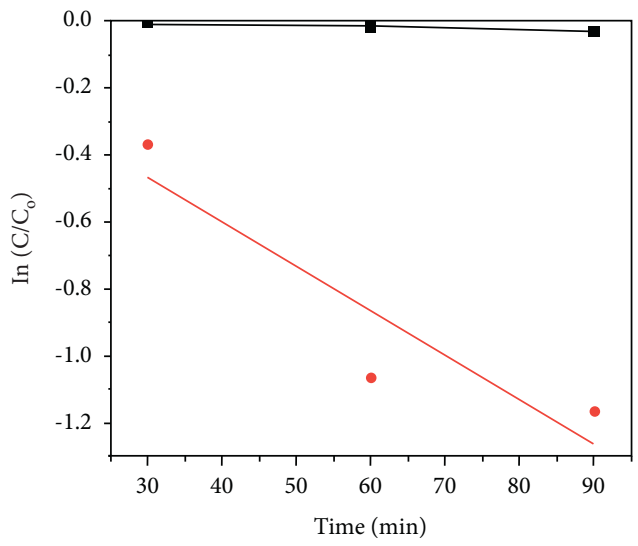

- Without $\mathrm{NiO}-\mathrm{ZnO}$

- With NiO-ZnO

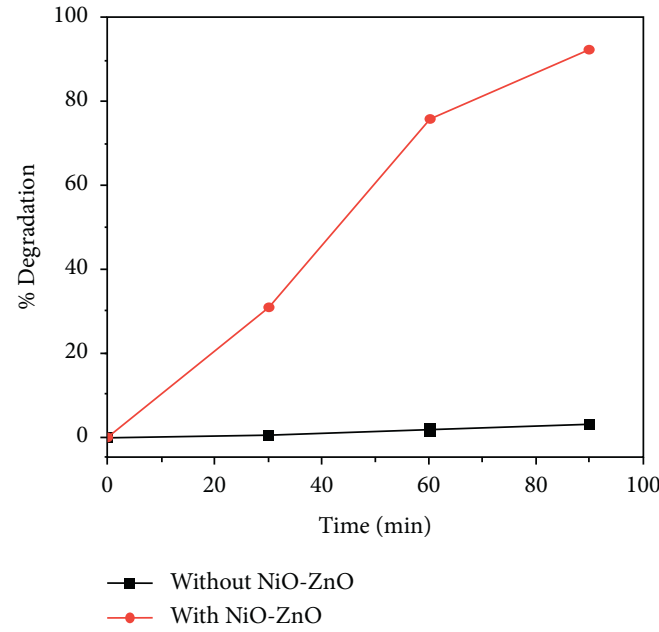

(b)

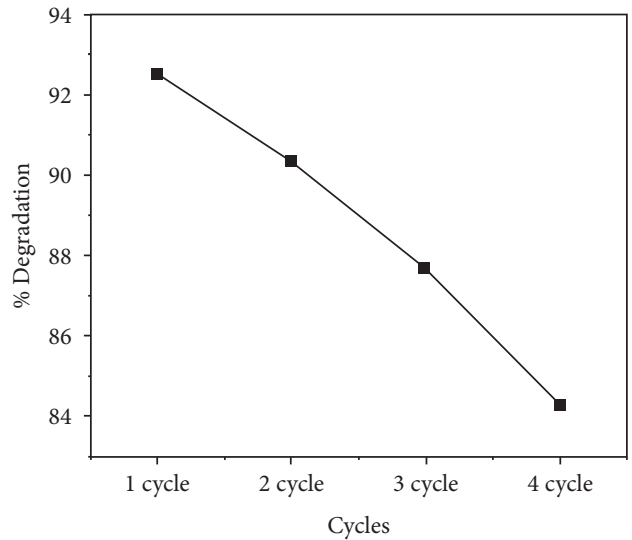

(c)

(d)

FIGURE 8: Photodegradation of BG. (a) Degradation profile, (b) percent degradation, (c) kinetic isotherm, and (d) reusability data.
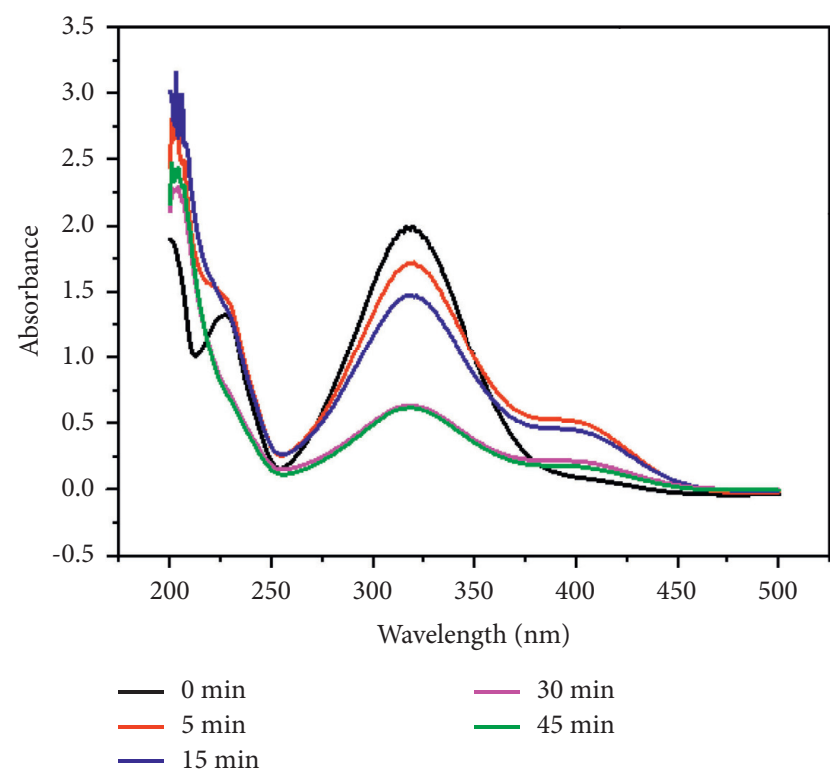

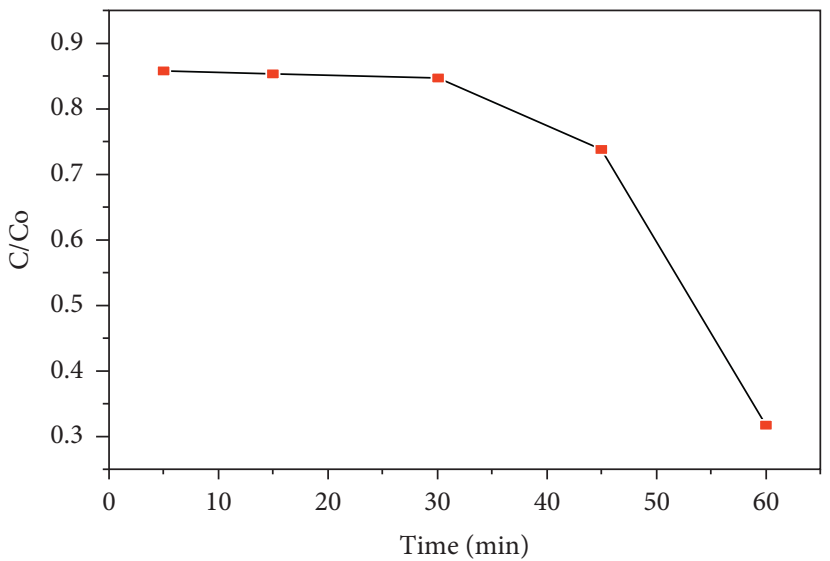

(a) 


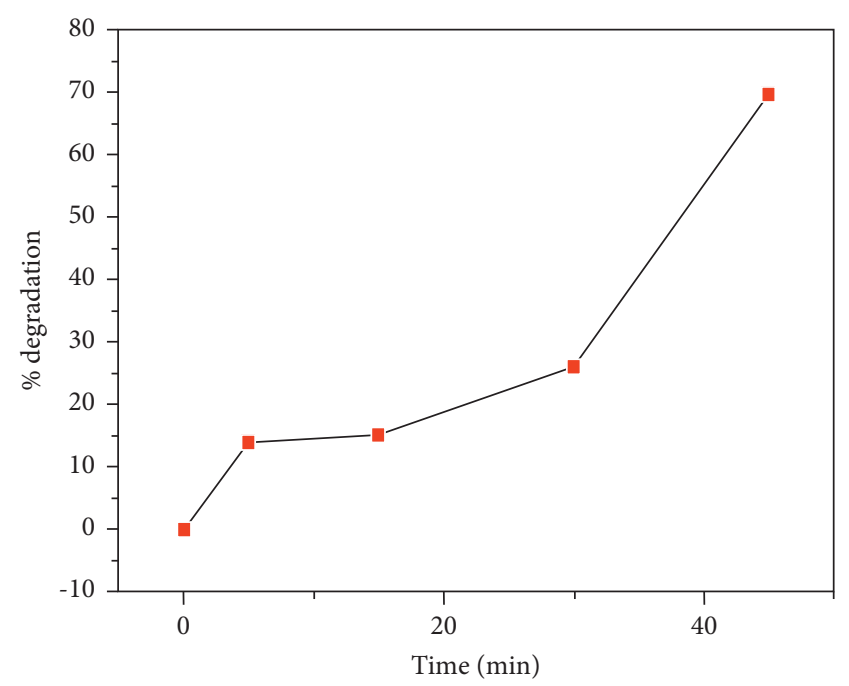

(c)

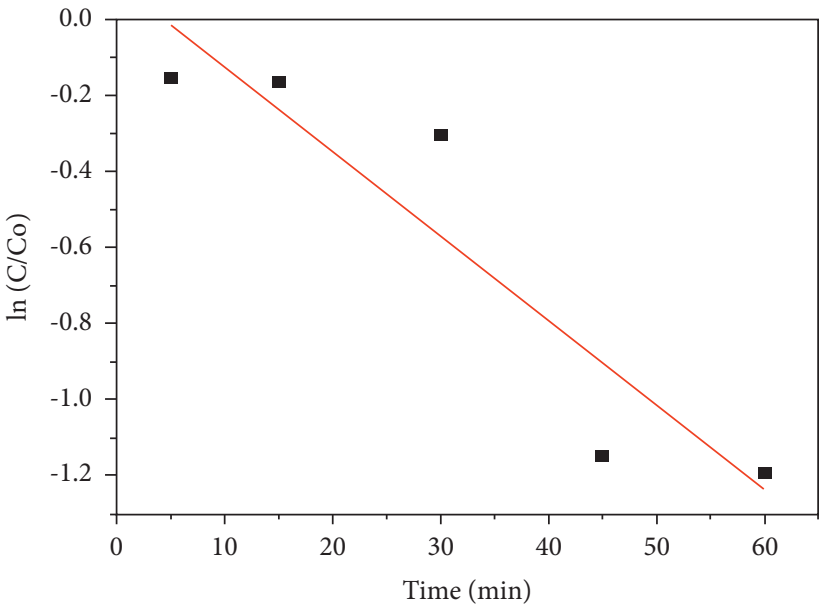

(d)

Figure 9: (a) Absorption spectra of 4-nitrophenol. (b) Degradation profile, (c) percent degradation, and (d) kinetic isotherm.

TABle 1: The photocatalytic efficacy of NiO-ZnO NC against different organic pollutants.

\begin{tabular}{lcccc}
\hline S. no. & Nanocatalysts & Time $(\mathrm{min})$ & Percentage degradation & References \\
\hline 1 & Rhodamine B & 120 & 70 & {$[17]$} \\
2 & Rhodamine 6G & 390 & 92.8 & {$[31]$} \\
3 & Methyl orange & 150 & 91.89 & {$[32]$} \\
4 & Eriochrome black T & 90 & 83.36 & {$[33]$} \\
5 & Methylene blue & 120 & 92.5 & {$[17]$} \\
6 & Brilliant green & 90 & 69.7 & Present work \\
7 & 4-Nitrophenol & 45 & Present work \\
\hline
\end{tabular}

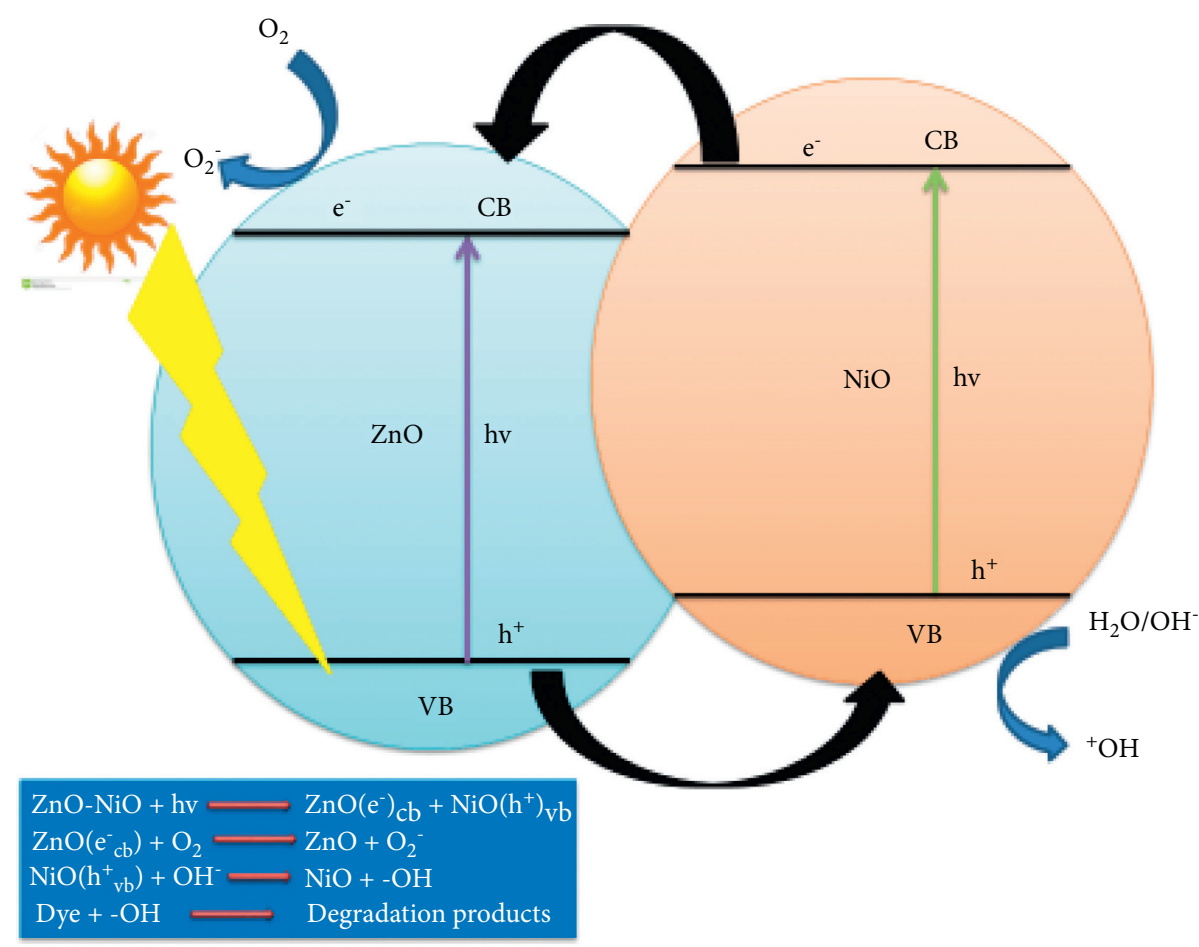

FIgURE 10: Schematic representation of electron flow during photocatalysis. 
the dye and convert it into harmless substances [30]. The set of chemical reaction given in Figure (10) summarizes the hole-electron shifting and degradation of BG and 4-NP.

\section{Conclusion}

To synthesize NiO-ZnO NC, green method was found to be a very efficient, fast, and economical process. FTIR and EDX confirmed the formation of binary nanocomposite. The XRD analysis shows that amorphous content was also present along with crystalline phase and also confirms the formation of hetero-structure. The band gap calculated from DRS for $\mathrm{NiO}-\mathrm{ZnO}$ was different from their individual nanoparticles which confirm the formation of new material. SEM reveals the roughness and agglomeration of particles after dehydration. The photocatalytic degradation of $\mathrm{NiO}-\mathrm{ZnO} \mathrm{NC}$ was checked against BG and 4-NP, which reveals that under the applied conditions, the NiO-ZnO NC shows marvelous photocatalytic performance and could be used in the future for waste water treatment on large scale.

\section{Data Availability}

The data used to support the findings of this study are included within the article.

\section{Conflicts of Interest}

The authors declare that they have no conflicts of interest.

\section{Acknowledgments}

The authors are grateful to the Deanship of Scientific Research for funding this article by Taif University Researchers Supporting Project number (TURSP-2020/28), Taif University, Taif, Saudi Arabia.

\section{References}

[1] P. Rasheed, S. Haq, M. Waseem, S. U. Rehman, and W. Rehman, "Green synthesis of vanadium oxide-zirconium oxide nanocomposite for the degradation of methyl orange and picloram," Materials Research Express, vol. 7, no. 2, pp. 1-8, 2020.

[2] M. Kaykhaii, M. Sasani, and S. Marghzari, "Removal of dyes from the environment by adsorption process," Chemical and Materials Engineering, vol. 6, no. 2, pp. 31-35, 2018.

[3] R. Jeyachitr, N. Sriharan, V. Senthilnathan, and T. Senthil, "Effect of Ni doping on structural, optical and photocatalytic properties of $\mathrm{Zn1-XNiXO}$ nanoparticles prepared by different $\mathrm{pH}$ conditions," Journal of Advances in Chemistry, vol. 12, no. 6, pp. 4097-4107, 2017.

[4] U. S. Udayachandran Thampy, A. Mahesh, K. S. Sibi, I. N. Jawahar, and V. Biju, "Enhanced photocatalytic activity of $\mathrm{ZnO}-\mathrm{NiO}$ nanocomposites synthesized through a facile sonochemical route," SN Applied Sciences, vol. 1, no. 11, pp. 1-15, 2019.

[5] M. A. Aly-Eldeen, A. A. M. El-Sayed, D. M. S. A. Salem, and G. M. El Zokm, "The uptake of eriochrome Black T dye from aqueous solutions utilizing waste activated sludge: adsorption process optimization using factorial design," The Egyptian Journal of Aquatic Research, vol. 44, no. 3, pp. 179-186, 2018.
[6] J. Š́ma and P. Hasal, "Photocatalytic degradation of textile dyes in aTiO2/UV system," Chemical Engineering Transactions, vol. 32, pp. 79-84, 2013.

[7] S. M. Hassan and M. A. Mannaa, "Photocatalytic degradation of brilliant green dye by $\mathrm{SnO}_{2} / \mathrm{TiO}_{2}$ nanocatalysts," International Journal of Nano and Material Sciences, vol. 5, pp. 9-19, 2016, Journal Homepage: https://www. ModernScientificPress.Com.

[8] V. Yadav, P. Verma, H. Sharma, S. Tripathy, and V. K. Saini, "Photodegradation of 4-nitrophenol over B-doped $\mathrm{TiO}_{2}$ nanostructure: effect of dopant concentration, kinetics, and mechanism," Environmental Science and Pollution Research, vol. 27, no. 10, pp. 10966-10980, 2020.

[9] R. Rehman, S. J. Muhammad, and M. Arshad, Brilliant Green and Acid Orange 74 Dyes Removal from Water by Pinus Roxburghii Leaves in Naturally Benign Way: An Application of Green Chemistry, 2019, 2019.

[10] S. Shoukat, W. Rehman, S. Haq, M. Waseem, and A. Shah, "Synthesis and characterization of zinc stannate nanostructures for the adsorption of chromium (VI) ions and photo-degradation of rhodamine 6G," Materials Research Express, vol. 6, no. 11, p. 115052, 2019.

[11] A. Ahmad, S. H. Mohd-Setapar, C. S. Chuong et al., "Recent advances in new generation dye removal technologies: novel search for approaches to reprocess wastewater," RSC Advances, vol. 5, no. 39, pp. 30801-30818, 2015.

[12] M. Pawar, S. T. Sendo, and P. Gouma, Review Article A Brief Overview of $\mathrm{TiO}_{2}$ Photocatalyst for Organic Dye Remediation: Case Study of Reaction Mechanisms Involved in Ce$\mathrm{TiO}_{2}$ Photocatalysts System, 2018, 2018.

[13] L. Singh, G. Goga, and M. K. Rathi, "Latest developments in composite materials," IOSR Journal of Engineering, vol. 02, no. 8, pp. 152-158, 2012.

[14] A. Hameed, V. Gombac, T. Montini, M. Graziani, and P. Fornasiero, "Synthesis, characterization and photocatalytic activity of $\mathrm{NiO}-\mathrm{Bi}_{2} \mathrm{O}_{3}$ nanocomposites," Chemical Physics Letters, vol. 472, no. 4-6, pp. 212-216, 2009.

[15] G. Sharma, A. Kumar, S. Sharma et al., "Novel development of nanoparticles to bimetallic nanoparticles and their composites: a review," Journal of King Saud University Science, vol. 31, no. 2, pp. 257-269, 2019.

[16] M. Vimal Kumar, T. S. Gokul Raja, N. Selvakumar, and K. Jeyasubramanaian, "Synthesis and characterization of NiO$\mathrm{ZnO}$ nanocomposite by a cost efficient self-combustion technique," Journal of Achievements in Materials and Manufacturing Engineering, vol. 79, no. 1, pp. 13-18, 2016.

[17] M. Hassanpour, H. Safardoust-Hojaghan, and M. SalavatiNiasari, "Rapid and eco-friendly synthesis of $\mathrm{NiO} / \mathrm{ZnO}$ nanocomposite and its application in decolorization of dye," Journal of Materials Science: Materials in Electronics, vol. 28, no. 15 , pp. 10830-10837, 2017.

[18] S. Kerli and Ü. Alver, "Preparation and characterisation of $\mathrm{ZnO} / \mathrm{NiO}$ nanocomposite particles for solar cell applications," Journal of Nanotechnology, vol. 2016, Article ID 4028062, 5 pages, 2016.

[19] S. Taheriniya and Z. Behboodi, "Comparing green chemical methods and chemical methods for the synthesis of titanium dioxide nanoparticles," International Journal of Pharmaceutical Sciences and Research, vol. 7, pp. 4927-4932, 2016.

[20] N. Bibi, S. Haq, W. Rehman et al., "Low temperature fabrication of $\mathrm{SnO}_{2}, \mathrm{ZnO}$ and $\mathrm{Zn}_{2} \mathrm{SnO}_{4}$ nanostructures for the degradation of Rhodamine 6G: characterization," Biointerface Research in Applied Chemistry, vol. 10, pp. 5895-5900, 2020. 
[21] K. Velmurugan, V. S. K. Venkatachalapathy, and S. Sendhilnathan, "Synthesis of nickel zinc iron nanoparticles by coprecipitation technique," Materials Research, vol. 13, no. 3, pp. 299-303, 2010.

[22] S. A. Khan, S. B. Khan, L. U. Khan, A. Farooq, K. Akhtar, and A. M. Asiri, "Fourier transform infrared spectroscopy: fundamentals and application in functional groups and nanomaterials characterization," Handbook of Materials Characterization, vol. 1, pp. 317-344, 2018.

[23] S. Nagarajan and K. Arumugam Kuppusamy, "Extracellular synthesis of zinc oxide nanoparticle using seaweeds of gulf of Mannar, India," Journal of Nanobiotechnology, vol. 11, no. 1, p. 39, 2013.

[24] A. O. Juma, E. A. A. Arbab, C. M. Muiva, L. M. Lepodise, and G. T. Mola, "Synthesis and characterization of CuO-NiO-ZnO mixed metal oxide nanocomposite," Journal of Alloys and Compounds, vol. 723, pp. 866-872, 2017.

[25] A. Attar and M. Altikatoglu Yapaoz, "Biosynthesis of palladium nanoparticles using Diospyros kaki leaf extract and determination of antibacterial efficacy," Preparative Biochemistry \& Biotechnology, vol. 48, no. 7, pp. 629-634, 2018.

[26] S. Haq, F. Abbasi, M. Ben Ali et al., "Green synthesis of cobalt oxide nanoparticles and the effect of annealing temperature on their physiochemical and biological properties," Materials Research Express, vol. 8, no. 7, Article ID 075009, 2021.

[27] M. M. Sajid, S. B. Khan, N. A. Shad, and N. Amin, "Synthesis of $\mathrm{Zn}_{3}\left(\mathrm{VO}_{4}\right)_{2} / \mathrm{BiVO}_{4}$ heterojunction composite for the photocatalytic degradation of methylene blue organic dye and electrochemical detection of $\mathrm{H}_{2} \mathrm{O}_{2}$," RSC Advances, vol. 8, no. 62, pp. 35403-35412, 2018.

[28] V. Karthikeyan, A. Padmanaban, T. Dhanasekaran et al., "Synthesis and characterization of $\mathrm{ZnO} / \mathrm{NiO}$ and its photocatalytic activity, mechanics," Materials Science \& Engineering, vol. 9, pp. 1-5, 2017.

[29] S. Haq, S. Shoukat, W. Rehman, M. Waseem, and A. Shah, "Green fabrication and physicochemical investigations of zinc-cobalt oxide nanocomposite for wastewater treatment," Journal of Molecular Liquids, vol. 318, Article ID 114260, 2020.

[30] A. Shah, S. Haq, W. Rehman, M. Waseem, S. Shoukat, and M.-u. Rehman, "Photocatalytic and antibacterial activities of Paeonia emodi mediated silver oxide nanoparticles," Materials Research Express, vol. 6, no. 4, Article ID 045045, 2019.

[31] S. Shoukat, S. Haq, W. Rehman et al., "Remediation of chromium (VI) and rhodamine 6G via mixed phase nickelzinc nanocomposite: synthesis and characterization," Journal of Inorganic and Organometallic Polymers and Materials, vol. 31, no. 4, pp. 1565-1575, 2020.

[32] J. Li, F. Zhao, L. Zhang et al., "Electrospun hollow $\mathrm{ZnO} / \mathrm{NiO}$ heterostructures with enhanced photocatalytic activity," RSC Advances, vol. 5, no. 83, pp. 67610-67616, 2015.

[33] M. Karimi-Shamsabadi, M. Behpour, A. K. Babaheidari, and Z. Saberi, "Efficiently enhancing photocatalytic activity of $\mathrm{NiO}-\mathrm{ZnO}$ doped onto nanozeoliteX by synergistic effects of p-n heterojunction, supporting and zeolite nanoparticles in photo-degradation of Eriochrome Black T and Methyl Orange," Journal of Photochemistry and Photobiology A: Chemistry, vol. 346, pp. 133-143, 2017. 